\title{
ESTUDO DAS EMISSÕES DE ÁLCOOL NÃO QUEIMADO E ALDEÍDOS EM VEÍCULO FLEX ANALISADAS PELAS TÉCNICAS DE CROMATOGRAFIA E FTIR.
}

\author{
Katia C.C. Silva ${ }^{1}$, Luiz Carlos Daemme ${ }^{1}$, Valeria Macedo ${ }^{1}$, Renato Penteado ${ }^{1.2}$ e \\ Sergio Machado Corrêa ${ }^{3}$ \\ ${ }^{1}$ Institutos Lactec \\ ${ }^{2} \mathrm{P} \& \mathrm{~K}$ Consultoria \\ ${ }^{3}$ Universidade Estadual do Rio de Janeiro - UERJ \\ E-mails: katia.silva@lactec.org.br, luiz.carlos@lactec.org.br, \\ valeria.macedo@lactec.org.br, renato@lactec.rg.br, sergio@air.pro.br
}

\section{RESUMO}

O álcool não queimado (ANQ) é encontrado nas emissões veiculares como resultado da queima incompleta do etanol na câmara de combustão dos motores. $O$ método de determinação de ANQ é normatizado e baseado em cromatografia em fase gasosa.

A quantificação de aldeídos também é normatizada e a técnica preconizada é da cromatografia em fase líquida.

Outra forma de determinação do ANQ e aldeídos é por FTIR, uma técnica cuja aplicação vem sendo difundida pelas vantagens que oferece.

A literatura internacional é carente de resultados comparativos obtidos pelas técnicas normatizadas e por FTIR (para os compostos citados), fato que motivou a realização deste estudo.

Para comparação das técnicas foi utilizado um veículo de passeio do ciclo Otto, que foi testado em bancada de dinamômetro chassis no ciclo FTP-75, utilizando-se combustíveis contendo diferentes teores de etanol, a saber: A22, A31, A85 e EHR.

As emissões foram medidas pelas técnicas de cromatografia e FTIR e os resultados foram tratados estatisticamente pela ferramenta ANOVA e Teste de Tukey. Para dar consistência estatística, um número mínimo de três testes foi executado com cada combustível.

Os resultados das medições de ANQ, por GC e FTIR, são apresentados em forma de gráficos e os valores revelam a mesma tendência, principalmente com uso dos combustíveis A85 e EHR. O mesmo comportamento foi observado para as análises de aldeídos.

\section{INTRODUÇÃO}


O álcool não queimado é encontrado nas emissões veiculares e é resultado da queima incompleta do etanol na câmara de combustão dos motores. É importante ressaltar que as emissões do etanol são consideradas como um dos precursores do ozônio troposférico [1] Em 1994, o CONAMA, por meio da Resolução no 9, estabeleceu uma norma para mensuração da emissão de álcool não queimado. $O$ método de determinação é baseado em cromatografia gasosa, segundo a NBR $15598 / 2008[2]$

A emissão de aldeídos é o resultado da oxidação de álcoois primários presentes nos combustíveis veiculares, quais sejam: gasolina C, etanol ou Diesel. O formaldeído é um carcinogênico conhecido, ao passo que o acetaldeído é considerado como um "provável" carcinogênico [3]. De acordo com Alvim et al. [4] na mistura de etanol na gasolina a emissão de acetaldeído é maior que do formaldeído em motores do ciclo Otto quando há presença do etanol no combustível. Por outro lado, esta situação se inverte quando o veículo é movido à gasolina. A NBR 12026/2009 descreve a metodologia para a determinação de aldeídos e cetonas em veículos automotores e quantifica as emissões através da cromatografia líquida de alta performance (CLAE), também conhecida na literatura como High Performance Liquid Chromatography (HPLC). Esta norma aplica-se aos veículos do ciclo Otto [5].

No ano de 2009, o etanol hidratado foi o agente causador de $60 \%$ da emissão de aldeídos em oposição a $38 \%$ da gasolina. A pesquisa do 1ำ Inventário Nacional também sinaliza uma estimativa do aumento significativo das emissões de aldeídos até 2020 , com $79 \%$ para o etanol hidratado, $18 \%$ com gasolina do tipo C e $3 \%$ do GNV. Tal tendência pode ser explicada pela expectativa que havia naquele inventário a previsão de uma expansão da utilização do etanol devido ao crescimento acelerado da frota de veículos flex [6]

O etanol também tem outra peculiaridade pelo fato de conter mais oxigênio na sua formação se comparado à gasolina, o que favorece a formação de hidrocarbonetos oxigenados reativos. Estes associados com a emissão de $\mathrm{NO}_{x}$ podem formar 0 ozônio troposférico e, por consequência, o "smog fotoquímico ".

Outro poluente é o álcool não queimado (ANQ) provocado pela queima parcial (incompleta) do combustível nas câmaras de combustão. A determinação do ANQ também é definida por uma norma brasileira, porém diferentemente dos aldeídos, não foram estabelecidos limites para sua geração. A medição de emissão de ANQ em um veículo Flex abastecido por combustíveis contendo diferentes teores de etanol é o foco deste trabalho.

Estudos da CETESB [3] e de Melo et al.[7] mostram que o álcool não queimado, os acetaldeídos e os COVs (compostos orgânicos voláteis) contribuem para a formação de ozônio na troposfera. $O$ álcool não queimado possui uma reatividade para a formação de ozônio maior que um conforme a tabela de Carter (1994).

O estudo realizado por Alvim [8] cita que o etanol na atmosfera é transformado em acetaldeído, composto com alta reatividade para formação de ozônio. 
As emissões de álcool não queimado em si são pouco reativas, mas como são emitidas em grande quantidade por veículos Flex, acabam sendo importantes na formação do $\mathrm{O}_{3}$. Uma parte do $A N Q$ é convertido em aldeídos por reações na atmosfera e esses poluentes são bastante reativos.

No ano de 2001, Poulopoulos et al [9] estudaram o efeito da adição de etanol à gasolina em emissões regulamentadas e não regulamentadas. Um veículo com motor de quatro cilindros, 1,6 L OPEL, foi alimentado com três combustíveis de ensaio. $O$ primeiro foi uma gasolina sem chumbo sem quaisquer aditivos oxigenados que foi usada como um combustível de referência e de base para a preparação de misturas gasolina / álcool. O segundo e o terceiro foram composições de gasolina e álcool contendo $3 \%$ e $10 \%$ de etanol $(\mathrm{v} / \mathrm{v})$, respectivamente. Para os combustíveis contendo etanol, as emissões de acetaldeído foram significativamente aumentadas (até 100\%), especialmente para o combustível contendo 3\% de etanol se comparado com a gasolina.

Em 2010, Shah et al.[10] realizaram um estudo sobre as emissões de aldeídos emanadas de um veículo leve bicombustível. O veículo foi alimentado alternativamente com combustíveis E10 e E0. Os resultados experimentais mostraram que durante o modo de operação transitório, as emissões de formaldeído diminuíram $46 \%$, enquanto que as de acetaldeído aumentaram em cerca de três vezes com E10, em comparação com o E0.

Kummar et al.[11] publicaram que para motores que utilizam a mistura de $10 \% \mathrm{v} / \mathrm{v}$ de etanol, a emissão de formaldeído aumenta cerca de $25 \%$, de acetaldeído em torno de $180 \%$ e acroleína aproximadamente $5 \%$, quando comparada ao veículo abastecido com gasolina pura sem adição de etanol. Os autores concluíram que os aldeídos são formados pela combustão incompleta de hidrocarbonetos.

Daemme, no ano de 2009, [12] realizou uma pesquisa comparando as metodologias tradicionais de medição de emissões veiculares com a técnica FTIR. Concluiu que os métodos são aplicáveis, porém ajustes no FTIR são necessários para que possa ser utilizado de forma direta nas pesquisas.

Daemme, em 2012, [13] realizou uma comparação entre a técnica de FTIR e cromatografia líquida, coletando simultaneamente os compostos de aldeídos. Concluiu que os resultados foram considerados estatisticamente iguais.

\section{METODOLOGIA}

\subsection{Especificação do veículo}

Um veículo de passageiros Flex Fuel, motor 1,6 litros, ano de fabricação 2009/SW, foi testado em um dinamômetro de chassis de acordo com a norma brasileira NBR 6601, ciclo FTP-75, em um laboratório de emissões localizado em Curitiba/Brasil.

\subsection{Especificação dos combustíveis}


O veículo foi abastecido com gasolinas A22, A31, A85 e etanol hidratado de referência (EHR). Emissões legisladas, $\mathrm{HC}, \mathrm{CO}, \mathrm{NOx}, \mathrm{CO}_{2}$ e $\mathrm{CH}_{4}$ foram medidas em bancadas de análise. Os aldeídos foram quantificados pela técnica de HPLC de acordo com a norma brasileira NBR 12026. O álcool não queimado foi medido utilizando duas técnicas: análise por FTIR e GC (NBR 15598).

Tabela 1 - Características dos combustíveis utilizados nos testes de emissão veicular

\begin{tabular}{c|c|c|c|c}
\hline \multirow{2}{*}{ Característica } & \multicolumn{4}{|c}{ Combustível } \\
\cline { 2 - 5 } Massa específica a 20을 $\mathrm{C}\left(\mathrm{kg} / \mathrm{m}^{3}\right)$ & EHR & A85 & A31 & A22 \\
\hline Teor de etanol (\% volume) & 808,1 & 794,4 & 747,1 & 745,6 \\
\hline
\end{tabular}

Fonte: os autores (2014)

\subsection{Cromatografia Gasosa}

As medições de ANQ foram determinadas pela metodologia NBR 15598/2008, utilizando um cromatógrafo de fase gasosa Agilent Tecnologies modelo 7890A GC Systems, com coluna cromatográfica capilar com diâmetro $0,53 \mathrm{~mm}$, comprimento de $30 \mathrm{~m}$, espessura do filme de 1,00 $\mu \mathrm{m}$, detector FID, injetor automático modelo Combi Pal - GC sampler 80 (microseringa para CG, medidor de vazão, totalizador do volume gasoso, frascos lavadores de gás em vidro e vidrarias).

\subsection{Cromatografia Liquida}

As emissões de formaldeído e acetaldeído foram medidas pela técnica de cromatografia líquida de alto desempenho ou high performance liquid chromatography (HPLC), de acordo com a norma ABNT NBR 12026/2009. A cromatografia líquida tem como aplicação geral a separação e análise de misturas de compostos não voláteis derivatizados com DNPH (2,4-dinitrofenilhidrazina). A norma ABNT NBR 12026/2009 prescreve o método para quantificação de aldeídos e cetonas contidos nos gases de escapamento emitidos por um veículo leve durante o ciclo de condução FTP-75. Os equipamentos utilizados foram: cromatógrafo HPLC Agilent modelo 1200/1260, bomba isocrática de alta pressão para HPLC (solvente $70 \%$ acetonitrila e 30\% água), amostrador automático e degaseificador, compartimento de coluna com controle de temperatura em média de $35^{\circ} \mathrm{C}$, coluna de fase reversa Zorbax Eclipse modelo XDB C18 de 4,6 de diâmetro e $250 \mathrm{~mm}$ de comprimento, partículas de $5 \mu \mathrm{m}$. Com detector VWS 1200 modelo G1314D espectrofotométrico UUV, sensível a comprimento de onda fixo $365 \mathrm{~m}$. Os reagentes utilizados são DNPH $\left(\mathrm{C}_{6} \mathrm{H}_{6} \mathrm{~N}_{4} \mathrm{O}_{4} \mathrm{H}_{2} \mathrm{O}\right)$, acetonitrila 99,7 \% $\left(\mathrm{CH}_{3} \mathrm{CN}\right)$, álcool metílico $99,5 \%\left(\mathrm{CH}_{3} \mathrm{OH}\right)$, álcool etílico $99,5 \%\left(\mathrm{C}_{2} \mathrm{H}_{5} \mathrm{OH}\right)$, ácido clorídrico $(\mathrm{HCl})$ e ácido perclórico $70 \%\left(\mathrm{HClO}_{4}\right)[5]$.

\subsection{FTIR}

Para o presente estudo, a vazão do gás de amostra para o analisador FTIR foi de 6 litros por minuto. A linha de coleta de amostra de gases foi aquecida a $190^{\circ} \mathrm{C}$. As medições foram realizadas nos gases de escape brutos (não diluídos). O esquema 
do procedimento de ensaio em dinamômetro de chassi e o equipamento de FTIR acoplado ao escapamento do veículo são mostrados na Figura 1

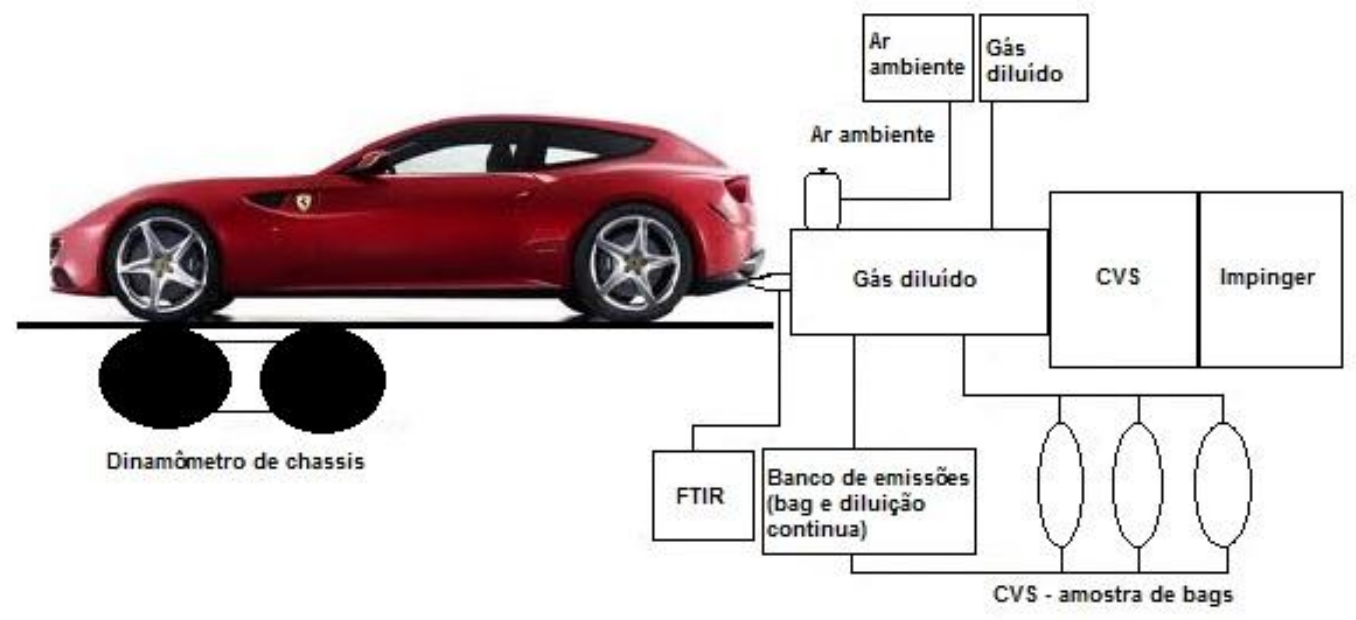

Figura 1 - Esquema dos ensaios de bancada de chassis e FTIR Fonte: os autores (2014)

\section{RESULTADOS}

\section{1Álcool Não queimado}

A Figura 2 apresenta os resultados das emissões de ANQ determinados pela técnica de CG. Os dados foram convertidos para $\mathrm{mg} / \mathrm{km}$ para uma melhor visualização gráfica.

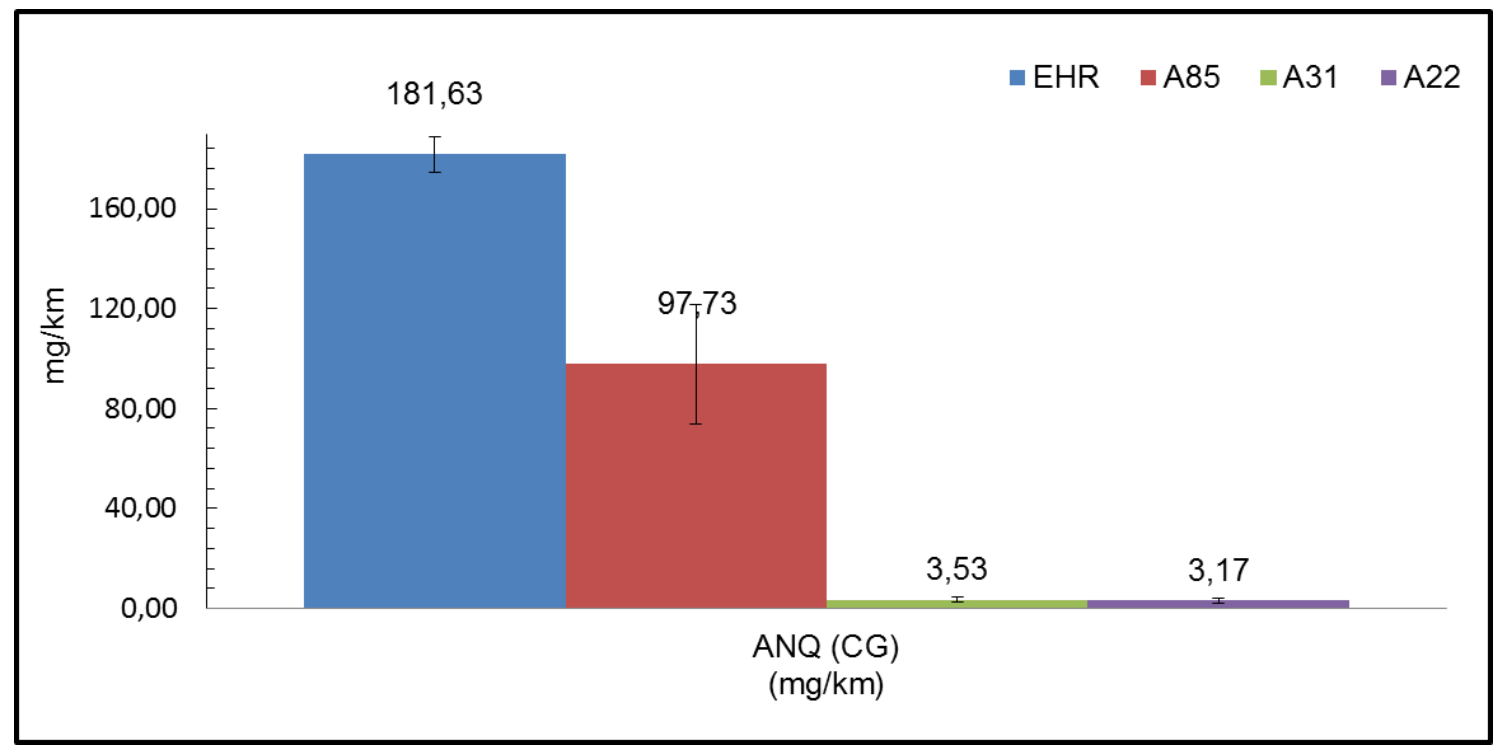

Figura 2 - Emissões de $A N Q$ pela técnica $C G$

Fonte: Os autores (2014)

Observa-se que as emissões de ANQ apresentam variação expressiva em função do teor de etanol adicionado ao combustível. Conforme esperado, as emissões de ANQ têm maior relevância no etanol hidratado de referência (EHR), se comparadas às demais misturas. O acréscimo de $15 \%$ de gasolina ao álcool anidro levou à 
redução de aproximadamente $50 \%$ da emissão de $A N Q$, entretanto com $69 \%$ de gasolina a emissão de ANQ cai 98\%.

\section{A}

Tabela 2 mostra os resultados de análise estatística para o poluente de álcool não queimado medido pela técnica de cromatografia gasosa.

Tabela 2 - Comparativo da ANOVA para o ANQ determinado pela técnica de CG

\begin{tabular}{lcccc}
\hline POLUENTE & \multicolumn{4}{c}{$\begin{array}{c}\text { ANQ - Técnica Cromatografia } \\
\text { gasosa }\end{array}$} \\
\hline Combustível & \multicolumn{4}{c}{ Comparação } \\
\cline { 2 - 5 } & EHR & A85 & A31 & A22 \\
\hline EHR & & $\neq$ & $\neq$ & $\neq$ \\
\hline A85 & & & $\neq$ & $\neq$ \\
\hline A31 & & & & $=$ \\
\hline
\end{tabular}

Fonte: Os autores (2014)

A Figura 3 mostra a aquisição de dados de álcool não queimado, a cada segundo do ciclo FTP-75, por FTIR. Nela pode ser observado que no início do ciclo, em sua fase fria, há uma geração de $A N Q$ em valores mais expressivos, se comparados com o restante do ciclo, possivelmente devido a uma maior injeção de combustível nesse regime. A partir da fase fria, as emissões tendem a uma estabilização.

Figura 4 - Emissões de ANQ (ppm) Gráfico segundo a segundo medição de emissões por FTIR- ciclo

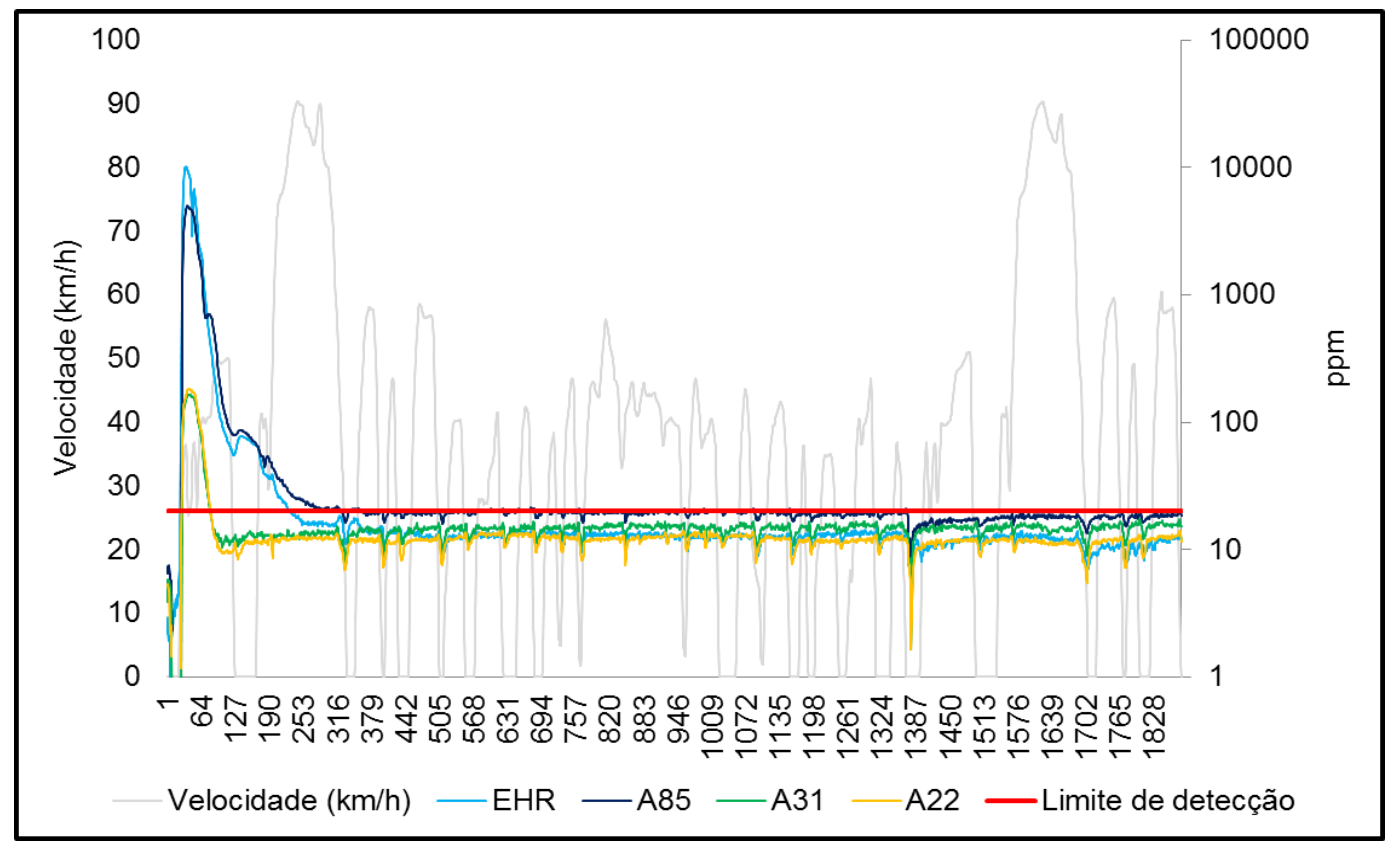

FTP-75

Fonte: Os autores (2014)

A Figura 4 apresenta os dados de emissão de ANQ da $1^{\text {a }}$ fase do ciclo FTP-75, para os diferentes combustíveis testados. 


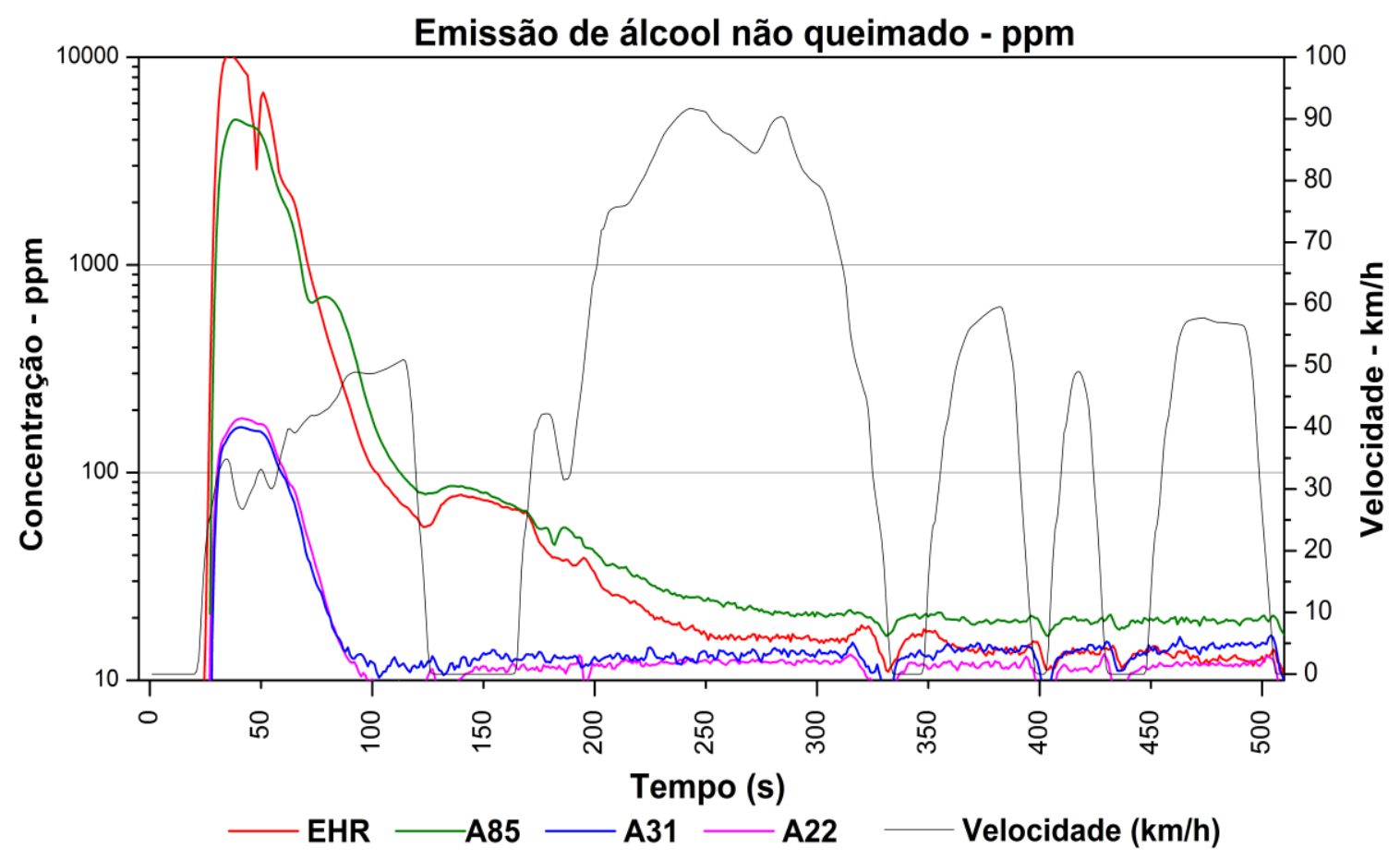

Figura 5 - Emissões de ANQ - $1^{\underline{a}}$ fase Fonte: Os autores (2014)

Observa-se que, aos primeiros segundos na partida a frio do veículo, a emissão de álcool não queimado é muito mais expressiva, tendendo à estabilização da emissão em aproximadamente $10 \mathrm{ppm}$.

A Figura 6 mostra dados que permitem uma comparação das duas técnicas utilizadas para os ensaios de álcool não queimado.

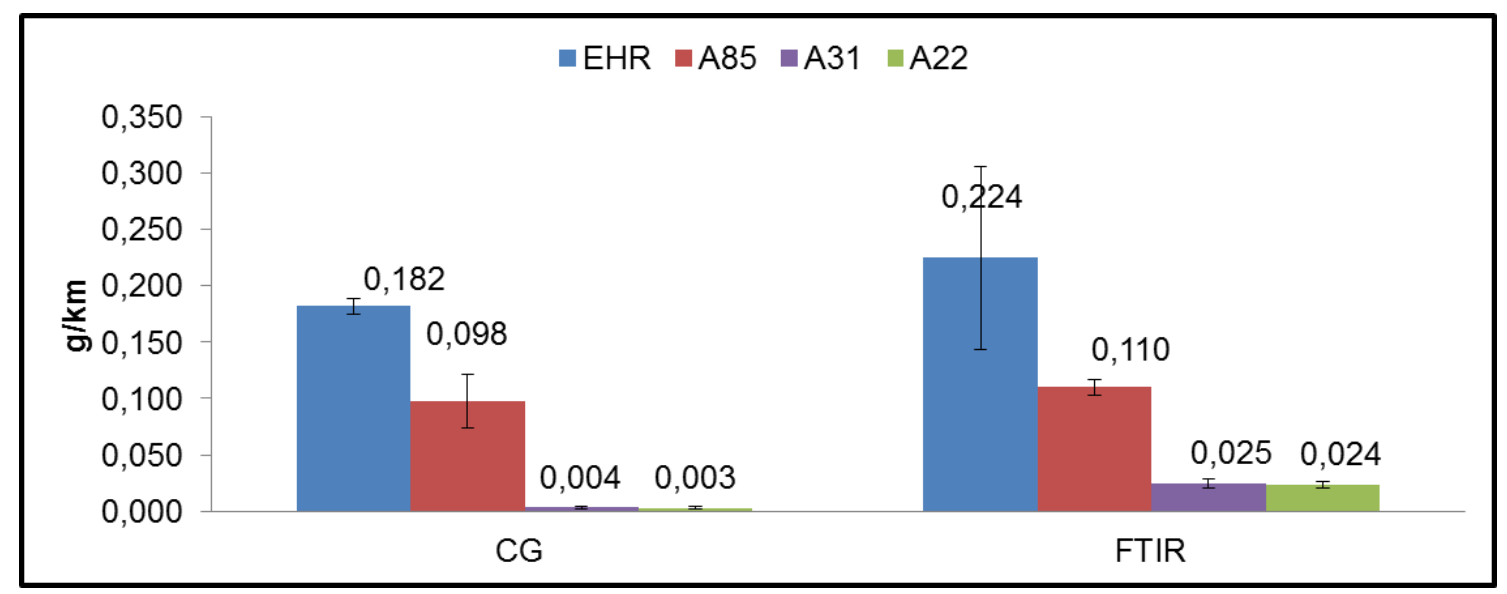

Figura 6 - Comparativo técnica de CG e FTIR com os combustíveis estudados

Fonte: Os autores (2014)

Verifica-se, por ambas as técnicas, que o teor de ANQ aumenta diretamente com a participação do etanol na mistura. Este fato era esperado.

\subsection{ALDEÍDOS}


Os valores do formaldeído, acetaldeído e aldeídos totais são mostrados na Figura 7.

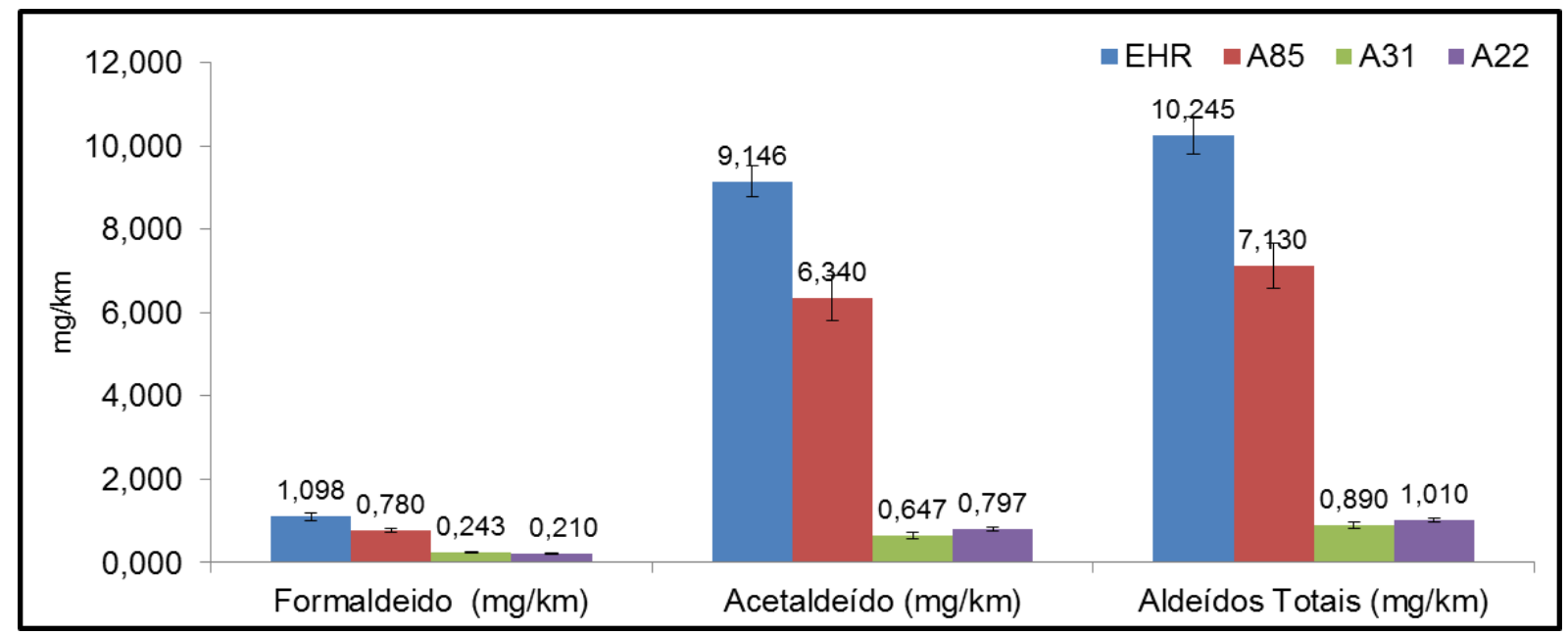

Figura 7 - Emissões de aldeídos

Fonte: Os autores (2014)

Observa-se que os resultados de formaldeído para os combustíveis e EHR e A85 estão semelhantes devido à elevada participação do etanol em ambas as misturas. Entretanto quando há o aumento de gasool (A22), ocorre uma queda de aproximadamente $81 \%$. Martins et al. [15] ressaltaram em seu trabalho que os motores a álcool possuem uma maior contribuição nas emissões de acetaldeído. $\mathrm{O}$ estudo realizado por Souza et al. [1] mostra que a emissão de acetaldeído e formaldeído no gás de escapamento é superior em veículos Flex Fuel quando abastecidos com EHR do que quando comparados com gasool A22.

A Tabela 3 apresenta os resultados da análise estatística para as emissões de formaldeído e acetaldeído obtidos pela técnica de cromatografia liquida.

Tabela 3 - Análise estatística das emissões de formaldeídos e acetaldeídos

\begin{tabular}{l|llll|llll}
\hline POLUENTE & \multicolumn{1}{l}{ Formaldeído } & \multicolumn{7}{c}{ Acetaldeído } \\
\hline \multirow{2}{*}{ Combustível } & Comparaça & \multicolumn{1}{c}{} & \\
\cline { 2 - 9 } & EHR & A85 & A31 & A22 & EHR & A85 & A31 & A22 \\
\hline EHR & & $\neq>$ & $\neq>$ & $\neq>$ & & $\neq>$ & $\neq>$ & $\neq>$ \\
\hline A85 & & & $\neq>$ & $\neq>$ & & & $\neq>$ & $\neq>$ \\
\hline A31 & & & & $=<$ & & & & $=<$ \\
\hline
\end{tabular}

Fonte: Os autores (2014)

\section{CONCLUSÃO}

Observou-se que os aldeídos aumentam com o teor de etanol na mistura do combustível.

As emissões de álcool não queimado aumentaram diretamente e de forma significativa com o etanol combustível. Com os veículos movidos a álcool são 
amplamente utilizados, o efeito do álcool não queimado na qualidade do ar não pode ser ignorado.

Os valores médios de $A N Q$, obtidos pela técnica de CG e FTIR revelam a mesma tendência, principalmente para A85 e EHR com a utilização da ANOVA esses resultados se confirmaram.

As emissões de ANQ são consideradas elevadas nos primeiros 250 segundos em comparação com o resto do ciclo FTP-75. Atribui-se este fenômeno à partida do motor na temperatura ambiente, e a dificuldade de partida a frio com etanol aliada ao tempo para o aquecimento do catalisador.

As conclusões apresentadas neste artigo foram fundamentadas nos resultados obtidos com testes no veículo analisado sendo, portanto, limitadas somente ao referido veículo.

\section{AGRADECIMENTOS}

Os autores agradecem ao Ministério da Ciência e Tecnologia e ao CNPq (Conselho Nacional de Desenvolvimento Científico e Tecnológico) pelo apoio à realização deste trabalho. Agradecem também à equipe do Laboratório de Emissões Veiculares do Lactec, onde foram realizados os testes de emissões, e ao PRODETEC (Programa de Pós-graduação em Desenvolvimento de Tecnologia).

\section{REFERÊNCIAS}

[1] SOUZA, R. B. de; FERREIRA, V.R.; ABRANTES, R. de; BORSARI, V.; Influência do etanol combustível na emissão de etanol, aldeídos e hidrocarbonetos expelidos pelo escapamento em veículos leves. São Paulo: AEA, 2013.

[2] BRASIL. MINISTÉRIO DO MEIO AMBIENTE, Resolução CONAMA no 9, de 04 de maio de 1994. Publicada no DOU 04.10.1994, Art.1ํㅡ, páginas 1.

[3] CETESB. Ficha de informação toxicológica: Formaldeído e Acetaldeído. Divisão de toxicologia, genotoxidade e microbiologia ambiental. 2012b. São Paulo. Disponível em: http://www.cetesb.sp.gov.br/tecnologia-ambiental/laboratorios/109informacoes-toxicologicas. Acesso em: 18 de janeiro de 2014 [4] ALVIM, D.S.; GATTI, V.N.; SANTOS, M.H.; YAMAZAKI,A. Estudos dos compostos orgânicos voláteis precursores de ozônio na cidade de São Paulo. Eng Sanit Ambient, v.16 n.2, abr/jun 2011, p. 189-196. 2011. [5] ABNT. NBR 12026: Veículos rodoviários automotores leves - Determinação da emissão de aldeídos e cetonas contidas no gás de escapamento, por cromatografia líquida - Método DNPH, Rio de Janeiro, 2009.

[6] BRASIL. Ministério do Meio Ambiente - MMA. IEMA - Instituto de Energia e Meio Ambiente (Org.). $1^{\circ}$ Inventário Nacional de Emissões Atmosféricas por veículos automotores rodoviários. Brasília,DF.Brasil, 2011. Disponível em: http://www.mma.gov.br/images/arquivo/80060/10 Inventario Nacional de Emissoes Atmosfericas por Veiculos Automotores Rodoviarios.PDF. Acesso em: 07 out. 2013.

[7] MELO, T. C. C.de; COLNAGO, K.; LOUREIRO, L.N. Implantação dos gases orgânicos do tipo não metano (NMOG) no Brasil. SIMEA. São Paulo, 2009. 
Disponível em:

www.aea.org.br/aea2009/downloads/simea09/apres pap/PAP0069.pdf Acesso em 25 de maio de 2013.

[8] ALVIM, D.S. Estudo dos Principais Precursores de Ozônio na Região

Metropolitana de São Paulo. 2013. 151 f. Tese (Doutorado) - Curso de Ciências Na Área de Tecnologia Nuclear, Departamento de Instituto de Pesquisas Energéticas e Nucleares, Universidade de São Paulo, São Paulo, 2013.

[9] POULOPOULOS, S.G.; SAMARAS, D. P.; PHILIPPOPOULOS, C. J. Regulated and unregulated emissions from an internal combustion engine operating on ethanol-containing fuels. Atmospheric Environment 35 (2001) 4399-4406. [10] SHAH, A.N., YUN-SHAN, G., HONG, Z. Aldehyde and BTX Emissions from a Light Duty Vehicle Fueled on Gasoline and Ethanol-Gasoline Blend, Operating with a Three-Way Catalytic Converter. Jordan Journal of Mechanical and Industrial Engineering. Volume 4, Number 3, June,2010 ISSN 1995-6665 Pages 340 -34.5 .

[11] KUMAR, S.; NAYEK, M.; KUMAR, A.; TANDON, A.; MONDAL, P.; VIJAY, P.; BHANGALE, U.D; TYAGI, D. "Aldehyde, Ketone and Methane Emissions from motor vehicle exhaust: A critical review". American Chemical Science Journal 1(1): 1-27, 2011

[12] DAEMME, L. C. Comparativo entre as metodologias tradicionais de medição de emissões veiculares com a técnica FTIR. Curitiba, 2009. Monografia (Especialização). Universidade Federal do Paraná: 2009.

[13] DAEMME, L. C.. Estudo da emissão de aldeídos em motociclos. Dissertação (Mestrado) - Instituto de Tecnologia para o Desenvolvimento - LACTEC, Programa de Pós-Graduação em Desenvolvimento de Tecnologia - PRODETEC. Curitiba, 2012.

[14] AVL. User instruction SESAM 4. Gaggenau, Alemanha, 2006. Catálogo de instrução e uso.

[15] MARTINS, E.M.M; ARBILLA, G.; BAUERFELDT,G.F; PAULA,M. Atmospheric levels of aldehydes and BTEX and their relationship with vehicular fleet changes in Rio de Janeiro urban área. Atmospheric Environment 0045-6535 (2007) 